\title{
A Framework Based on OEE and Wireless Technology for Improving Overall Manufacturing Operations
}

\author{
Martha-Patricia Garcia ${ }^{1}$, Javier Santos ${ }^{2}$, Mikel Arcelus ${ }^{2}$, and Elisabeth Viles ${ }^{2}$ \\ ${ }^{1}$ Instituto Tecnológico de Chihuahua II, Chihuahua, México \\ patytec2 @yahoo.com \\ ${ }^{2}$ TECNUN - School of Engineering, University of Navarra, San Sebastian, Spain \\ \{jsantos, marcelus, eviles\} @tecnun.es
}

\begin{abstract}
Manufacturers have the challenge to increase productivity given complex manufacturing environments. A source that provides substantial levels of productivity is the overall equipment effectiveness (OEE) metric, which is an indicator to improve not only equipment utilization; but also the overall manufacturing operations, because of the valuable information that comes from the availability, performance and quality rates. Although information technologies have been introduced, companies use manually recorder data and have complicated measurement procedures. As a consequence, inaccurate information is generated and opportunities to improve productivity are missed. This paper presents a continuous improvement framework based on Lean manufacturing philosophy, operated by a system of wireless devices to support the real time equipment performance metrics. In order to validate the framework, results of a case study are exposed.
\end{abstract}

Keywords: Continuous improvement, Total productive maintenance, overall equipment effectiveness, lean manufacturing, operations management.

\section{Introduction}

Manufacturers usually consider the overall equipment effectiveness (OEE) as a metric that is only related to maintenance activity, and they do not take into account other valuable OEE-information for improving their entire manufacturing operations; this valuable information comes only if companies have a set of precise elements such as: an accurate data, proper calculation of rates, and adequate analysis of information in order to identify and locate the six main losses proposed by Nakajima and other hidden production losses.

In this manufacturing edge the manufacturing environment is complex, there are many electronic systems, intelligent systems and software tools supported by information technologies (IT) available for equipment monitoring and control, which includes automatic data collection, OEE calculations and a variety of key performance indicators (KPI). However, many manufacturing companies are using as a traditional way, manually recorder data. Additionally, the use of sophisticated systems does not guarantee optimum improvements, particularly because of the lack of a proper continuous 
improvement methodology [8]. Thus, collecting accurate data, understanding manufacturing losses and adopting a suitable continuous improvement methodology are significant factors that this study is concerned with.

This paper presents a study for developing a continuous improvement framework, whose purposes are the accurate calculation of the OEE indicators and the systematic integration of improvement methodology based on lean manufacturing tools. This framework has the advantage of using a portable wireless system called Plug\&Lean (which is composed of a set of wireless devices) [12] to support the real time automated collection, calculation, and graphic presentation of data. The research methodology utilized is a case study.

\section{$2 \quad$ Literature Review}

Three theoretical concepts are relevant to our study: Lean manufacturing, Continuous Improvement and a combination of TPM and OEE:

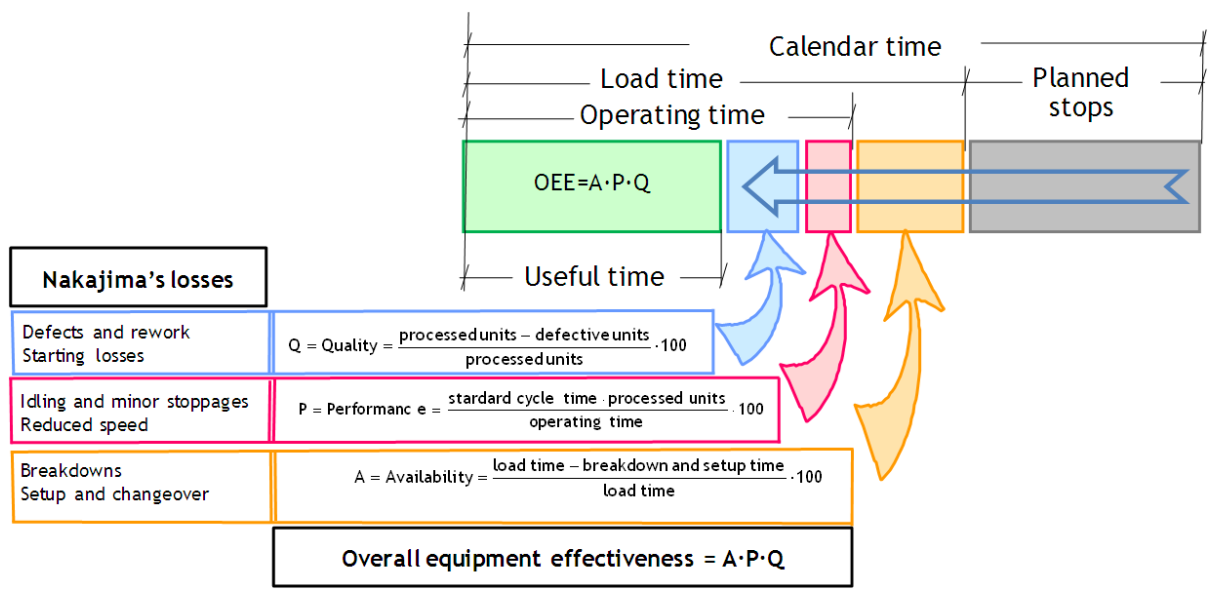

Fig. 1. The OEE and the six main losses [13]

- Lean manufacturing considered as an operational management philosophy focused on reducing waste in a manufacturing system. The literature defines waste as everything that increases cost without adding value for the customer [16]. This philosophy is composed of principles, methodologies and tools, and it functions on the basis of continuous improvement and worker involvement.

- Continuous improvement (CI) can be literally defined as continuous incremental improvement of the standard way of working [7]. The existing literature shows that there is no theoretical base for CI as a concept for what is considered into the quality terms given its attributes [2]. 
- TPM methodology [11] has been expanding significantly within manufacturing companies, because of the tangible results it provides. This is an improvement methodology developed by Nakajima, who proposes OEE as a measure that attempts to reveal hidden losses. The OEE calculation is split into three components: availability, performance and quality, which identify the six big losses (Figure 1).

\section{Related Work}

Bhuiyan and Baghel [3] state that although the continuous improvement (CI) methodology has evolved over the years, little research has been directed towards developing a model that allows organizations to structure a CI methodology that suits in a better shape to their needs and motivate an authentic participation of workers.

There are several studies on the Lean and OEE that result in different opinions about its potential. Grishnik and Winkler [6] state that companies avoid understanding all the component of an entire Lean implantation, missing gold opportunities to grow a better competitive position. Abdulmalek and Rajgopal [1] use a case study to demonstrate how lean manufacturing tools, when used appropriately, can help the process industry improve product quality and increases overall operational effectiveness.

Other authors [4] explored the use of the OEE not only as an operational measure but also as an indicator of process activities, and they concluded that the OEE should be balanced by other traditional measures. Jonsson and Lesshammar [8] proposed that planned downtime be taken into account as an important measure, and that it should be added to the OEE in order to have the whole picture of manufacturing performance. Ljungberg [9] discussed the importance of the personnel's understanding of the magnitude of and reason for machinery losses in order to provide an appropriate base for planning improvement activities; Dilorio and Pomorsky [5] proposed a TPM loss analysis model for generating accurate and non-theoretical OEE metrics; Wang and Pan [15] concluded that the process of collecting data in an automatically way provides high levels of accuracy in the OEE calculations and it makes it easier to see hidden losses.

\section{$4 \quad$ Research Methodology}

The methodology utilized in this study is the case study, which has been recognized as being particularly suitable for theory refinement [14]. According to Yin [17], a case study is a linear but iterative process where the experimental study shows primary results. Miles and Huberman [10] established that, in case study research, it is necessary to have very well defined key factors that lead to the expected results. The present study focuses on the development of continuous improvement activities as a systematic way of improving equipment efficiency, thus our key factors are equipment efficiency and continuous improvement, and the link between them conceptualizes our proposed framework. 


\section{The Framework}

The framework was developed as a functional framework based on the lean manufacturing philosophy and the operation is supported by the wireless Plug\&Lean-system. Figure 2 shows the frameworks's design. There are four specific objectives of the framework, which are described as follows:

- To automate the collection of equipment performance data in real time

- To display graphical information and charts related to the production performance indicators

- To determine the root cause of losses

- To drive towards to implement a structured methodology to improve manufacturing operations by using OEE information

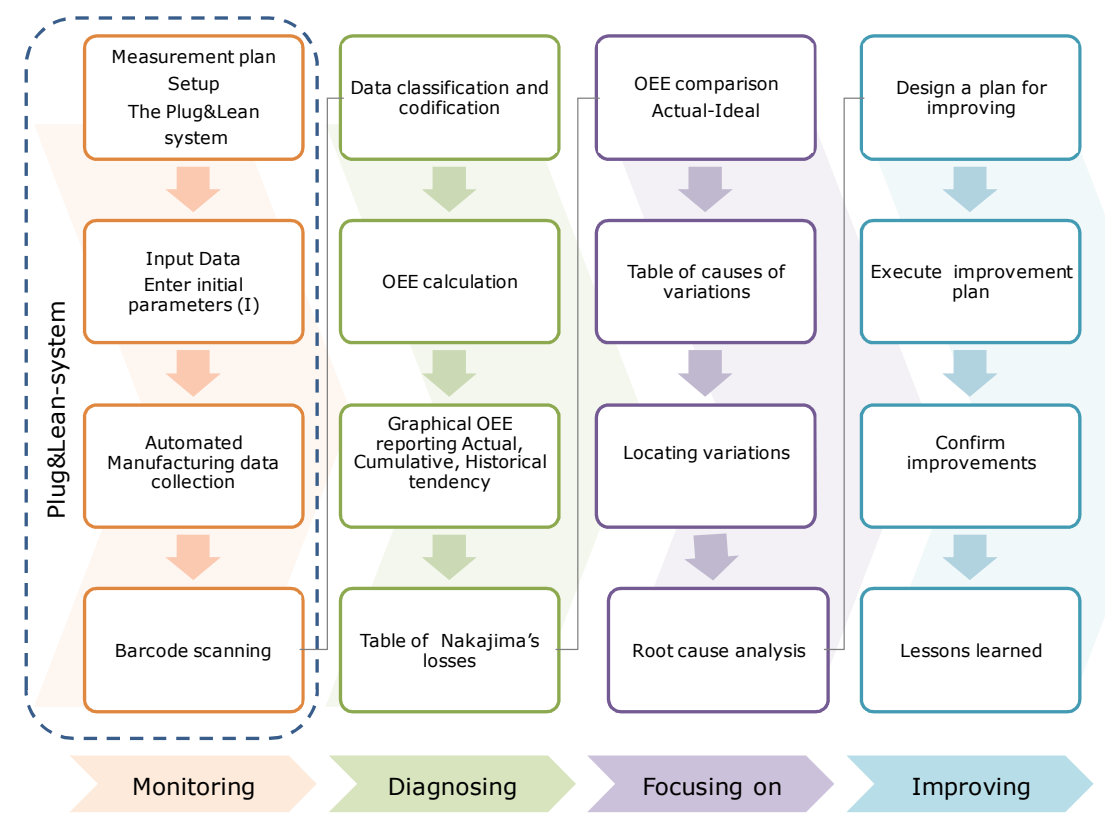

Fig. 2. The Plug\&Lean-CiMo framework's design

The operation of the overall framework depends on the processes, procedures and activities and their interrelation. This means that each process is represented by a procedure and a series of activities linked to the resources required for operating. The focus of this framework is: make bottom-line improvements with less effort in an easily structured way. 


\section{$5.1 \quad$ Plug\&Lean System}

The framework proposes the utilization of a new device to facilitate the gathering of data. The Plug to Lean wireless tool is a handle set of compact wireless components: sensors and a laptop computer, that seamlessly work together. It simply needs to be plugged into a designated area to sense the performance of equipment during a selected production time.

The device is not only for collecting data, it also contains software for displaying a series of events to conduct improvement actions in a focus area (Figure 3).

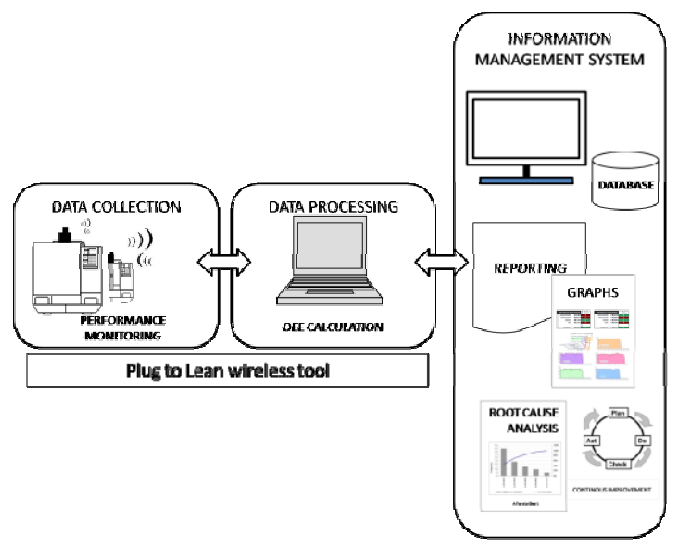

Fig. 3. The Plug\&Lean system schema

\section{$5.2 \quad$ Framework Operation}

This section describes the procedures, activities and resources required for each process whose descriptions are given in the following paragraph:

\subsubsection{Monitoring}

This stage encompasses the procedure for collecting the manufacturing data by monitoring the performance of equipment or production process during a period of time. This stage is composed of 2 processes: (1) setting up the Plug\&Lean system, and inputting the initial parameters, and (2) measuring the performance through the automated collection of data from machinery; a barcode system is utilized in order to scanner the codes of both the losses and the causes of performance variations presented. The gathered information is stored in a data-base.

\subsubsection{Diagnosing}

The Diagnosing stage is a procedure for processing the collected data and reporting real levels of OEE through graphics and charts in order to allow the examination of availability (A), performance (P), quality (Q), utilization (U) and OEE indicators. It uses software based on a conventional Microsoft application and Nakajima's theory of losses, taking information from the data-base. This stage comprises three processes: (1) conformation of the table of manufacturing data collected in order to make a 
classification; (2) determine the Nakajima's losses based on grouping and codifying the collected data; (3) Calculation of metrics and the graphical report. The graphical report consists on the presentation of current OEE indicators, the presentation of cumulative and historical OEE charts and the economic impact of losses.

\subsubsection{Focusing On}

The Focusing On stage is a procedure to analyze the information that comes from the diagnosis stage, for localizing and analyzing causes of performance variation in equipment. It is composed of three processes: (1) the analysis of losses by a comparison between actual and ideal OEE rates; (2) the localization of the losses through the 5M's; (3) the root-cause-analysis (RCA) which is supported by the seven quality tools, RCA methodology and other lean tools, in order to determine the source of losses.

\subsubsection{Improving}

The Improving stage is where a structured continuous improvement plan is developed in order to implement actions to eliminate or mitigate losses. This stage takes the information from the Focusing On stage, and then suggests for each kind of losses the suitable Lean manufacturing tools that should be implemented as a countermeasure. In addition, this stage is for confirming the improvements undertaken in terms of quality, cost and time. After confirmation of improvements, the lessons learned process is suggested.

\section{Case Study}

The manufacturing company we selected, as a case study, is located in the Basque region of Spain and operates three semi-automated and one automated continuous production lines. The continuous improvement framework was tested from May to December 2009, on the one automated line.

The first task carried out in the case study was to choose a multidisciplinary team member to plan the overall testing activities for the device. Meanwhile, another important task was conducted: an analysis to determine the procedure that the company was following at the time to collect data and how it calculated its efficiency or performance state. Next, OEE calculations were introduced to four automated production lines, a new classification of downtime was proposed, and a new way of teamworking to achieve improvement was suggested. One of the study reports is presented in Figure 4, which content a graphic which allows comparing indicator levels after implementing our framework.

Three important contributions was achieving during the study: (1) the company understood the importance of the identification of planned and non planned downtime as well as to count the re-work activity as a quality loss; (2) The company's management created its first multidisciplinary team formed by personnel from the quality, the maintenance and the production areas, they were involved in order to participate, and make suggestions and decisions during the implementation of the framework; and (3) the company's acceptance of the OEE metrics and the adoption of the framework. 


\section{Performance Rates Line 4}

Week: 44 Year: 2009
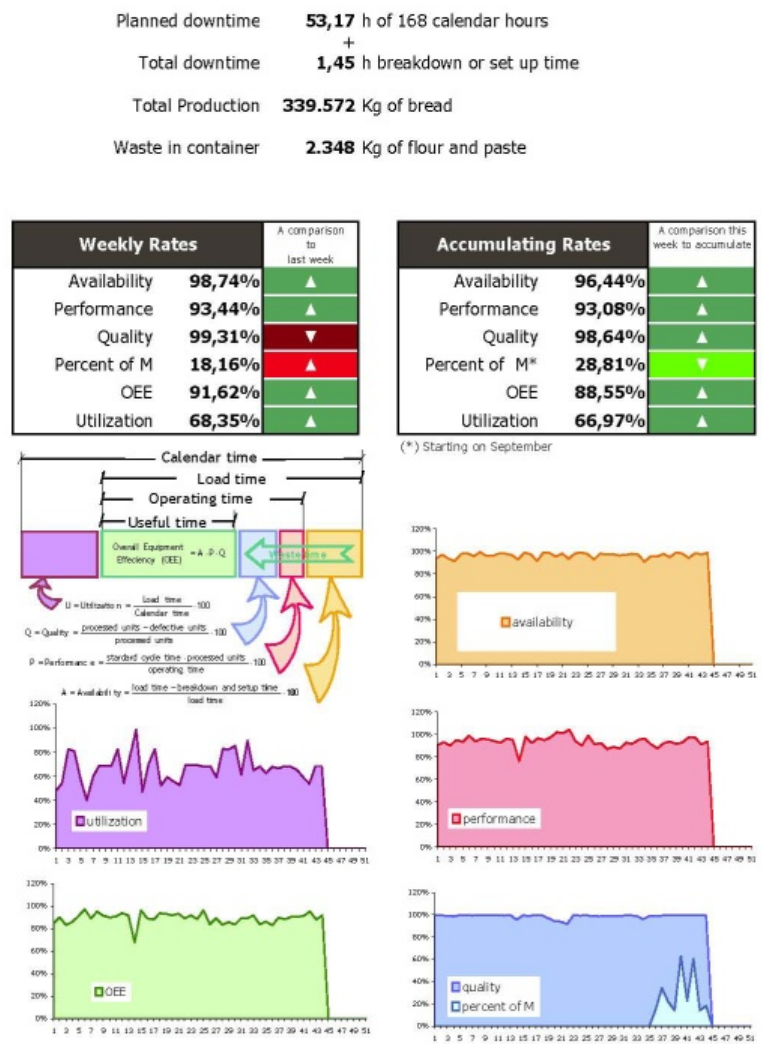

Fig. 4. Case study reporting graph

\section{Conclusions}

The proposed framework is driven by two key factors: the OEE indicators and the continuous improvement methodology. The advantage of the framework is that it operates with a structured CI methodology and accurate information thanks to the integration of the Lean manufacturing tools and the Plug\&Lean system. The framework was tested on a continuous manufacturing production line, and future work related to this study will be to test the framework in a discrete manufacturing system. The study's contributions are: the integration of a cutting edge wireless device in the field of operations management, not only for maintenance but also for continuous improvements activities and a valuable affordable procedure for businesses, especially small ones, that increases efficiency in the entire manufacturing operation. 


\section{References}

1. Abdulmalek, F.A., Rajgopal, J.: Analyzing the benefits of lean manufacturing and value stream mapping via simulation: a process sector case study. IJPE 107(1), 223-236 (2007)

2. Besant, J., Calfyn, S., Gallagher, M.: An evolutionary model of continuous improvement behavior. Technovation (21), 67-71 (2001)

3. Bhuiyan, N., Baghel, A.: An overview of continuous improvement: from the past to the present. Management Decision 43(5), 761-771 (2005)

4. Dal, B., Tugwell, P., Greatbanks, R.: Overall equipment effectiveness as a measure of operational improvement. A practical analysis. IJOPM 20(12), 1488-1502 (2000)

5. Dilorio, S., Pomorski, T.: SEMI Equipment Performance and Productivity Measurement Methods, Algorithms, and Standards. In: Brooks-PRI Automation, Asia User Conference, Shanghai (2003)

6. Grishnik, K., Winkler, C.: Make or break. How manufacturers can leap from decline to revitalization. McGraw-Hill, Company, USA (2008)

7. Imai, M.: Kaizen. The key to Japan's competitive success. Random House, Inc., Canada (1986)

8. Jonsson, P., Lesshammar, M.: Evaluation and improvement of manufacturing performance measurement systems - the role of OEE. IJOPM 19(1), 55-78 (1999)

9. Ljungberg, O.: Measurement of overall equipment effectiveness as a basis for TPM activities. IJOPM 18(5), 495-507 (1998)

10. Miles, H., Huberman, M.: Qualitative data analysis: A sourcebook. Sage Publications, Beverly Hills (1994)

11. Nakajima, S.: Introduction to TPM. Productivity Press, Cambridge (1988)

12. Santos, J., Garcia, M.P., Arcelus, M., Viles, E., Uranga, J.: Development of a wireless Plug\&Lean system for improving manufacturing equipment diagnosis. IJCIM 24(4), 338$351(2011)$

13. Santos, J., Wysk, R.A., Torres, J.M.: Improving production with Lean thinking. John Wiley\& Sons, Hoboken (2006)

14. Voss, C., Tsikriktsis, N., Frohlich, M.: Case research in operations management. IJOM 22(2), 195-219 (2002)

15. Wang, T.Y., Pan, H.C.: Improving the OEE and UPH data quality by automated data collection for the semiconductor assembly industry. Expert System with Applications 38, 5764-5773 (2010)

16. Womack, J., Jones, D.: Lean Thinking. Simon and Schuster, New York (1996)

17. Yin, R.: Case Study Research Methods. Sage Publishing, Newbury Park (1994) 